\title{
Reforma psiquiátrica e os trabalhadores da saúde mental - a quem interessa mudar?
}

Psychiatric Care reform and mental health workers - Change in whose interest?

Jamila Zgiet ${ }^{1}$

1 Mestre em Política Social pela Universidade de Brasília (UnB) - Brasília (DF), Brasil.

Servidora da Secretaria de Estado de Saúde

do Distrito Federal - Brasília (DF), Brasil.

jamilazgiet@gmail.com
RESUMO $O$ artigo aborda a reforma psiquiátrica na perspectiva dos trabalhadores da saúde mental, entendendo-a como estratégia capaz de garantir melhor atendimento às demandas dos usuários e melhores condições de trabalho aos servidores. Parte-se do pressuposto de que um serviço de saúde mental baseado nos princípios da reforma psiquiátrica dispõe de trabalhadores mais satisfeitos e mais saudáveis. O presente artigo se baseia em uma pesquisa de mestrado realizada no Distrito Federal, dando ênfase a grupos focais compostos por trabalhadores da saúde mental, desenvolvidos no único hospital psiquiátrico da unidade da federação e em um Centro de Atenção Psicossocial (CAPS). Verificouse, a partir da análise de conteúdo, que o ambiente manicomial provoca ou contribui para o sofrimento e o adoecimento mental dos trabalhadores.

PALAVRAS CHAVE: Reforma Psiquiátrica; Trabalho em Saúde; Saúde Mental.

ABSTRACT This article addresses psychiatric care reform from the perspective of the mental health workers, viewing it as a strategy to guarantee better response to user demands and better working conditions. It builds on the premise that a mental health care service based on the principles of psychiatric care reform will lead to a more satisfied and healthier work force. This article is based on master's degree research conducted in the Brazilian Federal District with focus groups composed of mental health workers from the only local psychiatric hospital and a Psychosocial Care Centre (CAPS). Content analysis led to the conclusion that the psychiatric hospital environment caused or contributes toward the mental sickness and suffering of the workers.

KEYWORDS: Psychiatric Care Reform; Health Work; Mental Health. 


\section{Introdução}

Este artigo é fruto de pesquisa realizada durante mestrado em Política Social no Departamento de Serviço Social da Universidade de Brasília. A dissertação foi defendida em setembro de 2010, sob o título 'Reforma psiquiátrica no Distrito Federal: um estudo sobre os obstáculos ao processo de implementação'. Durante a elaboração da pesquisa, não se buscava qualquer aproximação à questão da saúde dos trabalhadores da saúde, uma vez que se tinha como objetivo compreender os fatores que apareciam como obstáculos à adoção real da política de saúde mental brasileira pelo Distrito Federal (DF). A unidade da federação vem sendo considerada a mais atrasada na substituição de serviços manicomiais por centros de atenção psicossocial e outros equipamentos preconizados pela reforma psiquiátrica no Brasil. Isso fica claro no nono número da publicação 'Saúde mental em dados', do Ministério da Saúde (BRASIL, 2011), em que o Distrito Federal aparece com uma cobertura de 0,21 CAPS para cada 100 mil habitantes, abaixo de todas as outras unidades da federação.

A relação entre o tema e os trabalhadores da saúde mental é evidente, pois são estes os profissionais que devem colocar em prática o que consta na legislação. O trabalho em saúde mental é, geralmente, um desafio, pois é marcado por frustraçóes que vão da cronificação do quadro do usuário cuja doença se pretende tratar até a impossibilidade de controle do processo de trabalho. A forma como os serviços são organizados e a expectativa quanto à relação dos servidores com os pacientes também são fatores capazes de corroborar as dificuldades do cotidiano dos profissionais.

\section{Considerações sobre o método}

A realidade nacional é muito diversa quanto à implementação da reforma psiquiátrica, e o Distrito Federal apresenta-se em desvantagem importante, o que convida a pensar a possibilidade de uma incongruência entre a proposta local e a Lei Federal, nos sentidos político, prático e ideológico, o que resulta, dentre outros fatores, de conflitos de interesses entre formuladores, gestores, profissionais, familiares e usuários desses serviços.

Parte-se do pressuposto de que a saúde, sendo uma política social pública, é produto de relações contraditórias entre cultura e história, Estado e sociedade, capital e trabalho, liberdade e igualdade. Essa política é entendida como mais do que provisão e alocação de recursos pelo Estado para sua aplicação sobre a sociedade. É, assim, fruto de escolhas e decisóes que ocorrem na arena conflituosa de poder, tendo também, como política de ação, perfil, funçôes e objetivos próprios (PEREIRA, 2008).

Dessa forma, alguns fatores não podem ser deixados de lado na análise proposta: a configuração histórica e estrutural da elite política e sua influência na elaboração e na implantação das políticas; a participação dos demais atores (especialmente, familiares e profissionais) no processo de formulação, implementação e avaliação das açôes; os conflitos entre os atores políticos; a legislação em vigor e sua evolução; a relação entre a política de saúde mental e a política de saúde, e entre esta e as demais políticas; além das teorias e dos paradigmas orientadores das açóes na área. A pesquisa que originou este artigo pretendia verificar como esses aspectos vêm sendo construídos e organizados no Distrito Federal e de que forma afetam a política de saúde mental atual.

A partir dos fatores considerados fundamentais na análise de políticas sociais e da forma como se apresentam no caso da política de saúde mental - em especial, no contexto atual, de reforma do paradigma orientador de suas açóes -, consideraram-se hipóteses de resultados para a pesquisa: (a) a existência de conflitos entre os subsetores da saúde, em uma competição por recursos, no âmbito da gestão na esfera local; (b) a resistência de algumas categorias profissionais, principalmente dos médicos psiquiatras, às propostas de reforma encaminhadas pelo governo federal; (c) baixa politização do assunto nos espaços comuns aos familiares e aos usuários, e na mídia, perceptível no baixo número de organizações e manifestações da sociedade civil para reivindicar e defender os direitos desse grupo; (d) a manutenção do chamado "manicômio 
mental" (PÈLBART, 1991) por gestores e profissionais de saúde e pelos próprios familiares, o que representa o campo ideológico resistente às mudanças trazidas pela reforma psiquiátrica.

A resistência que se esperava observar entre médicos e outros profissionais e familiares não diz respeito somente a um aspecto subjetivo de rejeição às modificaçôes ou discordância quanto aos seus princípios. Ao contrário, acreditava-se que ela fosse influenciada diretamente pela implementação equivocada e incompleta do novo modelo de atenção à saúde mental. Também se imaginava que entre os profissionais militantes ou defensores da reforma psiquiátrica houvesse uma elaboração crítica a respeito da lei e do que tem sido considerado ideal nessa política, além de uma visão diferenciada a respeito de sua implementaçáo no $\mathrm{DF}$, de modo que ficassem aparentes os verdadeiros obstáculos à concretização do novo formato de atenção à saúde mental.

Considerando ser a metodologia "o caminho e o instrumento próprios de abordagem de realidade" (MINAYO, 1993, p. 22), faz-se necessário construí-la conforme o objeto que se pesquisa. A pesquisa social reflete posições frente à realidade e, nela, o objeto tem consciência histórica (MINAYO, 1993).

No campo metodológico, busca-se uma aproximação dialética, a partir da compreensão histórica não linear da realidade, em que as condições materiais determinam as ideias. Demo (1995) lembra que a história, mais do que representar um contexto para um fenômeno, o explica. "Toda formação social, movida por conflitos estruturais, produz necessariamente (forma) uma nova (história)", o que permite que se afirme que “o histórico é estrutural” (DEMO, 1995, p. 121).

A pesquisa aqui apresentada tem maior afinidade com o que Bulmer (apud DEMO, 1995) chama de pesquisa estratégica, a qual, segundo o autor, utiliza os instrumentos da pesquisa básica, mas tem a ação como finalidade e é orientada para os problemas da sociedade. Enfoca aspectos da realidade de modo a ser útil para o conhecimento e a avaliação de políticas, inclusive a de saúde.

As fases da pesquisa envolveram análise teórica e documental, grupos focais, entrevistas semiestruturadas e observação. A elaboração textual da dissertação ocorreu ao longo das fases, com tempo específico para isso ao final da investigação empírica. A análise teórica e documental compreendeu a leitura e a seleção de suporte teórico à pesquisa. Essa fase esteve em curso desde o início da elaboração do projeto, principalmente no que se refere à saúde mental e à reforma psiquiátrica, mas também foram utilizadas produções teóricas do campo das políticas sociais e da política de saúde.

A realização de grupos focais foi precedida por uma aproximação dos locais cujos profissionais e/ou usuários foram convidados a participar. A escolha do método dos grupos focais se deu pela sua capacidade de abranger mais instituiçôes e atores sociais, além de confrontar pontos de vista a partir da experiência dos participantes. Por meio dele, é possível enfatizar a interação em detrimento do monólogo obtido em entrevistas.

[...] a pesquisa com grupos focais tem por objetivo captar, a partir das trocas realizadas no grupo, conceitos, sentimentos, atitudes, crenças, experiências e reaçôes, de um modo que não seria possivel com outros métodos. (MORGAN, KRUEGER apud GATTI, 2005, p. 9).

Não se deve confundir grupo focal com entrevista coletiva. Segundo Kitzinger (apud GATTI, 2005), o interesse não é somente "no que as pessoas pensam, mas em como pensam e porque pensam assim” (p. 39).

Os temas abordados nos grupos de profissionais foram:

- A psiquiatria diante das outras especialidades médicas (remuneração, poder, demanda);

- O papel da psiquiatria na instituição;

- Saúde mental em relação a outras áreas de atuação (fatores positivos e negativos de se trabalhar com saúde mental);

- Relação entre as categorias profissionais (fatores positivos e negativos da realização de trabalho multiprofissional);

- Diferença entre os serviços prestados em saúde mental no Distrito Federal (compreensão 
de como os profissionais veem o serviço em que estão inseridos considerando a reforma psiquiátrica);

- Dificuldades encontradas no trabalho;

- Opiniáo sobre a proposta de reforma psiquiátrica da Lei no 10.216/01;

- Concepção do momento político no Distrito Federal e da atuação estatal no setor saúde;

- Engajamento em movimentos sociais.

Para a elaboração da dissertação, concomitantemente aos grupos focais, foram realizadas entrevistas com representantes de entidades não contempladas nos grupos, como a Gerência de Saúde Mental (GESAM), sendo que foram entrevistados o gestor atual e outro da época em que a GESAM ainda era Coordenadoria de Saúde Mental - COSAM, no período em que foi aprovada a Lei no 10.216/01 (BRASIL, 2001). Por fim, e com o objetivo de tratar do assunto sob vários pontos de vista, foram contatados representantes do Movimento Pró-Saúde Mental e da Associação Psiquiátrica de Brasília (APBr). A APBr, entretanto, não respondeu a nenhuma das solicitaçóes de participação na pesquisa, que foram feitas via fax, telefone e e-mail (institucionais e pessoais) para o diretor atual da entidade, durante o período de um ano. Assim, foram analisados os números do Jornal Brasiliense de Psiquiatria disponíveis no site da associação.

Neste trabalho, serão tratadas as falas dos profissionais participantes dos grupos focais realizados, considerando principalmente seus vínculos institucionais: o único hospital psiquiátrico público do DF ou o Centro de Atençâo Psicossocial (CAPS), ambos localizados em Taguatinga, região administrativa do DF. O hospital continua em funcionamento, mesmo havendo lei local de 1995 proibindo a existência de hospitais especializados em psiquiatria vinculados ao Sistema Único de Saúde (SUS) a partir de 1999. Há pronto-socorro e internação, com capacidade para 120 pessoas, entre homens e mulheres, além de servi- ços ambulatoriais, de hospital dia e um programa que realiza acompanhamento domiciliar.

Os grupos focais contaram com a participação de profissionais de nível superior, convidados e estimulados a discutir o assunto. Iniciou-se com as impressões obtidas no grupo focal realizado no hospital psiquiátrico. Em seguida, foram abordadas as discussóes expressas no grupo do CAPS. Por fim, buscou-se relacionar as informaçôes entre si e com a produção teórica existente e construída na dissertação mencionada.

O projeto de pesquisa foi submetido à apreciação e à avaliação do Comitê de Ética em Pesquisa da Secretaria de Estado de Saúde do Distrito Federal, sob o número 213/09, e foi aprovado no parecer 192/09, emitido em 12 de agosto de 2009. Para a garantia dos direitos e para o respeito aos aspectos éticos, na cessão de entrevistas e participação em grupos focais, foi utilizado termo de consentimento livre e esclarecido para cada participante, em duas vias, com assinatura do participante e da pesquisadora.

\section{Ser trabalhador de um hospital psiquiátrico em tempos de reforma}

O grupo focal realizado no único hospital especializado em psiquiatria do Distrito Federal teve a participação de quatro servidores de nível superior, sendo uma psiquiatra, dois psicólogos e uma enfermeira. O debate desenvolveu-se melhor nesse grupo, que foi menor, do que em outros, que contaram com a participação de até dez pessoas. Houve muita dificuldade na mobilização de pessoas para comporem o grupo focal no Hospital São Vicente de Paulo (HSVP). Isso se deveu, principalmente, ao horário de trabalho dos profissionais, que não permitia pausas para a participação na pesquisa. Houve também resistência das pessoas em participar, sob a justificativa de que desconheciam a reforma psiquiátrica.

Os servidores do grupo focal em discussão foram questionados a respeito do papel do psiquiatra na instituição e informaram tratar-se de uma prática médica tradicional, que guia o funcionamento do hospital. Essa opiniáo foi compartilhada por todos os 
profissionais. A prática médica no local resumir-se-ia, portanto, a

\section{[...] medicar, controlar [...] ligando os sintomas} com patologias. [...] eu sou o médico. O paciente chega com sintomas e acaba se enquadrando numa patologia e dai para o tratamento medicamentoso ou alguma coisa a mais, sem abrir muito o leque para ver outras questóes daquele individuo. [...] O nosso papel aqui é determinar como é que esse hospital tem que funcionar. [...] Tudo está em funçâo do médico.

Outro servidor complementa:

\section{[...] é o papel tradicional do psiquiatra num hospital psiquiátrico. São plantóes, internação, ambulatório. A grande massa de atendimentos está nesses serviços tradicionais.}

Outra reitera: "O que a gente vê é ainda aquele modelo antigo". Os profissionais demonstram conhecer a proposta de reforma psiquiátrica e, em suas falas, o termo 'antigo' aparece como sinônimo de 'manicomial'.

Ao abordar a questão do trabalho interdisciplinar, as participaçóes levam a crer que a centralidade no médico não diz respeito somente à organização dos serviços, mas a decisóes importantes nos níveis gerencial e terapêutico. Um exemplo é a definição do momento da alta dos pacientes internados:

Só sai de alta se não tiver mais delírio. Aí, fica aqui até 40 dias. [...] não é muito o que eu vejo, mas se tivesse essa decisão compartilhada da alta, poderia até reduzir [o tempo de internação], porque cada profissional, na sua área, poderia ver os pontos positivos para o paciente ficar em casa.

Uma participante do grupo afirma que os profissionais têm dificuldade em trabalhar em equipe, e que "acaba cada um no seu quadradinho". Outro, por seu turno, diz enxergar "uma corporação do saber, uma dificuldade de interação dos conhecimentos".
A esse respeito, Franco Basaglia (1985) apresenta uma avaliação da hierarquia necessária ao funcionamento da instituição psiquiátrica tradicional, discutindo, inclusive, a relação interprofissional. Para isso, se utiliza do exemplo de Gorizia, na Itália, em 1961. A realidade relatada pelo autor é compatível àquela relatada pelos profissionais no grupo focal.

A contradição fundamental entre a instituição como mecanismo e o doente enquanto objeto de cura, esta sim, faz com que o poder esteja totalmente localizado no primeiro dos dois termos; as características de sua distribuição, entretanto, são - e em Gorizia eram - complexas e contraditórias. Acima de tudo, por mais articulada e estratificada que seja a hierarquia da autoridade interna, existe e atua uma solidariedade homogênea entre os vários niveis, baseada na concordância objetiva quanto aos fins operativos institucionais: médicos e pessoal de apoio, todos depositários consentâneos de um mesmo mandato social de cura e custódia, e parte integrante de um mesmo mecanismo funcional, agem de maneira solidária e unânime, cada um com seu modelo técnico, na intençâo de atingir e conservar o objetivo institucional. A possessão em comum do mesmo objeto de exercício do poder - a massa dos doentes - facilita a distribuição das funções hierárquicas entre as diversas categorias profissionais e no interior das mesmas. Assim, $o$ doente é o único intermediário, passivo, da comunicação operativa entre as diversas categorias [...]. No mais, essas categorias permanecem fechadas em seus interesses corporativos e dentro dos parâmetros sócio-culturais das respectivas castas. (BASAGLIA, 1985, $\mathrm{p}$. 159-160).

Assim, o autor considera que, apesar da centralidade do médico psiquiatra, os servidores da instituição contribuem de alguma forma para a manutenção da ordem encontrada no hospital. Vale ressaltar que a lógica institucional se perpetua apoiada na alienação 
dos trabalhadores, inconscientes do todo ao qual a sua prática pertence, ou mesmo no seu desejo explícito de manter a organização tradicional do estabelecimento. A relação entre os profissionais se dá, portanto, por meio dos pacientes, que, em alguns momentos, colocam desafios à equipe, bem como a necessidade de tomada de decisôes. Não há, no entanto, reuniôes periódicas, discussão de casos e atividades com a participação de mais de uma categoria profissional. Embora os profissionais reconheçam a importância das outras categorias, evitam extrapolar o que é sua atribuição típica.

Ressalvadas as exceçóes, a psiquiatria no HSVP é a mesma criticada pelos pensadores do tema nos anos 1970 e 1980; mantém uma prática centralizadora, com foco no modelo biomédico, distante das propostas da chamada reforma psiquiátrica.

A forma como os profissionais são cobrados também influencia a qualidade do trabalho prestado. Os médicos, como destacou uma servidora, têm a obrigação de atender um número mínimo de pacientes por turno de atividade no ambulatório. Isso faz com que eles se apressem em atender esse mínimo no menor tempo possível, para deixar o local. Há uma preocupação da Secretaria de Estado de Saúde com a quantidade de atendimentos. Não há meios de avaliação do serviço que considerem a percepção dos usuários, assim como não há índices em busca da qualidade do atendimento.

A relação entre os servidores de diferentes categorias também sofre com essa forma de cobrança dos médicos, uma vez que os outros profissionais não têm a opção de gerar a produtividade mínima ao invés de cumprirem uma carga horária predefinida. Isso indica que a comunicação já parte de patamares diferenciados, em que o médico ocupa posição privilegiada.

O ambiente hospitalar psiquiátrico, cujo cenário é composto de grades, enfermarias cheias, barulho incômodo e odor que remete à insalubridade, contribui muito para a insatisfação dos profissionais. Esse cenário somado aos personagens - usuários, familiares e trabalhadores - na relação já exposta acima cria condiçóes favoráveis à difusão do sofrimento entre todos.

Ao serem questionados sobre a diferença entre trabalhar com saúde mental e trabalhar em outras áreas da saúde, os participantes da pesquisa seguiram um raciocínio que privilegiou a expressão das dificuldades encontradas nesse campo de atuação. Um deles trouxe à tona uma angústia quanto à organização institucional e à própria demanda do serviço de saúde mental.

[...] eu acho que o impacto da saúde mental é muito violento para os profissionais. É uma coisa angustiante. No serviço público, as pessoas estão por concurso, não é uma coisa de muita opção [...] Eu acho que tem dois tipos de angústia: a do sofrimento psíquico em si, que ele provoca no profissional de saúde, e a angústia da organizaçâa do serviço, no tipo, na equipe de organização do serviço. No hospital, você assume a responsabilidade sobre o paciente isso acontece em qualquer hospital-, o cuidado é de responsabilidade do profissional, mas na saúde mental, a demanda do paciente psiquiátrico é mais angustiante do que em outras clínicas. [...] a demanda do paciente psicótico é a demanda da loucura, uma coisa desorganizada que nem é explícita necessariamente e coloca em xeque a sanidade mental do cuidador.

Na perspectiva dos servidores do hospital psiquiátrico, a angústia mencionada se deve ao fato de o campo de atuação ser a saúde mental e não ao local de trabalho. Isso é corroborado pela fala de outra profissional, que abordou as diferenças na prática médica e a frustração em relação ao prognóstico do paciente: “[...] tem que lidar com uma frustração nesse sentido: receber a pessoa e, às vezes, não devolver ela tâo bem para a família. $\mathrm{Ou}$ você devolver bem e ela voltar pior".

Para o grupo, da mesma forma como Basaglia (1985) salientou em trecho citado acima, o públicoalvo influencia a relação estabelecida entre profissionais e usuários, e dentro da própria equipe. Isso também determina práticas corriqueiras reprodutoras da lógica manicomial, como a fala de um trabalhador destaca:

Eu acho que é a regra do hospital psiquiátrico. São as defesas. A primeira é fugir do paciente. A segunda é: não tendo jeito, ignore-o. Isso é o que me vem. Mas gera mais angústia, porque 
o paciente passa a ser visto como nada. Isso aumenta a ansiedade da equipe, porque não tem efetividade nenhuma, porque ele náo interage, não tem uma ação terapêutica minimamente eficaz. É iatrogênico, é insalubre, é ruim para todo mundo. [...] ai, o profissional também fica sem lugar. Ele tem um sofrimento que não é assumido, ele não pode falar: esse negócio "tá" ruim. Na instituição, não tem espaço para dizer "isso está ruim", "eu queria ir para outro lugar", "eu vim para cá porque não tem muita opçãa”.

Questionada sobre a diferença entre o hospital e os serviços substitutivos, como os CAPS, uma profissional afirma: "[...] aqui é um modelo de internação que existe no DF, o hospício. É aqui que vai ficar todo mundo que não pode ficar lá fora”. A mesma profissional aproveita o ensejo para manifestar sua insatisfação com o ambiente de trabalho e chega a se emocionar ao relatar seu retorno após um período de afastamento por atestado:

Eu não estava nesse serviço até algumas semanas atrás e estava achando ótimo. Acho que vou chorar agora. [pausa e pranto] Dá para ver que é estressante, gera consequências do adoecimento dessas pessoas que estão aqui, porque a gente sabe e se sente capacitado para atuar dessa outra forma, mas é impedido. Por conta de politicas, interesses outros, a gente acaba caindo nesse modelinho tradicional).

A fala dos profissionais expressa uma demanda importante no campo da atenção à saúde mental do trabalhador da saúde. Durante o grupo, os servidores se referem a situaçóes vividas por eles no ambiente de trabalho, sempre demonstrando mágoa e desesperança. O HSVP é, para eles, uma fonte de frustração, pois lá não é possível colocar em prática o que são capazes de fazer como profissionais. Isso se deve às dificuldades impostas pelo contexto político do Distrito Federal, em especial, da Secretaria de Estado de Saúde. As dificuldades de implementação da reforma psiquiátrica estão vinculadas diretamente às dificuldades de implementação do SUS. Apontam-se, como problemas do hospital, a falta de recursos, a dificuldade de trabalhar em equipe e a inexistência de rede de serviços que atenda às demandas, entre outros, que não sâo exclusividade do hospital psiquiátrico.

\section{O trabalho no serviço psicossocial}

O grupo focal realizado no CAPS de Taguatinga (GFC), em $1^{\circ}$ de setembro de 2009 , contou com a participação de mais servidores, entre terapeutas ocupacionais, enfermeiras e psicólogas, porque ocorreu no horário de reunião da equipe, momento desconhecido pela maioria dos profissionais do HSVP. A fala das oito profissionais participantes, já no início, contrasta com a do grupo anterior, no que se refere ao trabalho em equipe.

A interdisciplinaridade aparece em diversos momentos do debate, como prática corriqueira. Questionadas sobre como concebem a psiquiatria, como ramo da medicina, as participantes afirmaram que poucos são os profissionais médicos que atuam sob a perspectiva da reforma psiquiátrica. Consideram isso um empecilho ao trabalho em equipe, uma vez que os médicos terminam por se preocupar unicamente com a medicação, deixando outros aspectos fora do tratamento. Dizem também ser importante que o psiquiatra tenha perfil para atuar em CAPS, pois esse é um trabalho diferente do cotidiano de um ambulatório. Segundo uma profissional, o médico "de CAPS tem que ter todo um envolvimento". Outra trabalhadora concluiu

[...] que é muito da cultura mesmo do médico, esse atendimento do clínico, de consultório, vamos dizer assim, de ir lá, atender, passar a medicação e pronto. E, pra aplicar a teoria, a reforma, isso dificulta muito, porque tem o trabalho em equipe, interdisciplinar, transdisciplinar. Quem sabe, um dia? [risos] Só que, assim, realmente o profissional fica mais afastado da equipe. 
Em comparação com outros subsetores da saúde, a saúde mental é vista como estigma, não só como área de atuação. Os pacientes dos serviços de saúde mental também sofrem preconceito. Um exemplo citado por uma participante é de pacientes com transtorno mental que procuram o centro de saúde para acompanhamento de alguma outra especialidade.

Se ele [o profissional do Centro de Saúde] souber ou a pessoa relatar que é acompanhada num tratamento psiquiátrico, ele acha que a pessoa só tem a cabeça [...] e não tem a necessidade desse outro atendimento".

O ponto de vista que enfatiza a posição ocupada pelos usuários dos serviços não foi provocado, surgindo natural e prioritariamente no debate antes que se expusessem as situaçóes envolvendo os trabalhadores.

As profissionais manifestaram suas percepçóes sobre trabalhar em saúde mental. A maioria não tinha interesse anterior em atuar na área. Grande parte se disse apaixonada pelo campo de atuaçáo. As servidoras relataram, entretanto, que são estigmatizadas por seu trabalho. Informaram que as pessoas perguntam se não têm medo de lidar com 'doidos', se é perigoso; e que, muitas vezes, elas mesmas são consideradas 'loucas'. "As pessoas dizem "é doida de fazer isso".

O encantamento em relação à área de atuação é comentado por uma das presentes, destacando o fato de o CAPS ser um ambiente de trabalho diferenciado:

E o que encanta também muito, talvez mais do que o próprio objeto em si - a questão dos transtornos, do sofrimento psíquico - são as possibilidades de tratar. [...] a prática que eu cheguei a ver era muito triste, muito feia, mas aqui eu ressignifiquei: "Ah, saúde mental é isso? E trabalhar em um lugar legal assim? É trabalhar em uma casa bonita assim?". Talvez seja o nosso contexto, né? "De uma forma integrada assim?". Então, eu acho que o dispositivo ajudou a gente a construir essa imagem. Porque, se não fosse, eu não sei se eu teria essa visáo positiva, assim tão feliz... Porque o que eu sempre gostava, que en sabia, era que en tinha perfil para um trabalho psicossocial. Isso eu sabia. Essa atuação comunitária, social, de enxergar o social além do individual, isso eu sei que eu já trazia um pouco, eu gosto. Ai, eu trabalho em um dispositivo que pede, precisa e permite, permite essa dinâmica, permite ser criativo, permite ter um roteiro e sair dele, porque tem isso ai. Então, trabalhar com esse jogo de cintura, esse imprevisivel assim, que a saúde mental pede, essa forma de trabalhar, eu já gostava. Trabalhar aqui, podendo funcionar assim, é apaixonante. (GFC, 2009).

A atuação interdisciplinar, apesar de ser considerada difícil, dá ao trabalho um aspecto mais leve, graças à corresponsabilização dos profissionais.

A grande vantagem que eu acho dessa abordagem, dessa forma de atendimento, é você olhar para o sujeito enquanto individuo, enquanto sujeito e náo enquanto doente ou olhar para o CID dessa pessoa, para a doença que ela tem, mas estar olhando para esse sujeito, estar dando espaço para que ele possa se colocar enquanto pessoa, né?, se expressar. Esse espaço de escuta [...].

Eu não acho pesado o trabalho aqui, sinceramente. Não fica pesado. [...] a gente sabe que chegam aqui para a gente questóes muito complexas, sofrimento, dor doida mesmo, sofrimentos intensos. [...] o trabalho suga a gente, mas repóe. [...] eu me sinto assim, que a gente doa muito de si, a gente doa horário de almoço, a gente doa do tempo do corredor, a gente está o tempo inteiro nisso, mas eu acho que é muita troca mesmo. [...] Na verdade, a gente ver as coisas acontecendo não é uma utopia. Tem pequenos milagres acontecendo todo dia aqui. Você pensa que é impossivel e o que parece impossivel acontece aqui. Enão é pesado, eu acho, porque não é só para um. [...] É uma responsabilidade compartilhada, até onde eu enxergo. 
Então, eu me sinto suficientemente responsável por aquela situação. Acho isso uma das coisas mais legais aqui.

Tais falas surgem no debate, em meio à percepção coletiva das dificuldades de gestão da saúde como política pública. Ou seja: mesmo no mesmo contexto institucional amplo em que os servidores do hospital psiquiátrico estão, o trabalho no CAPS é mais satisfatório. As servidoras não deixam de observar a falta de material, o baixo número de profissionais e outros aspectos, mas, ainda assim, se veem como privilegiadas devido à oportunidade de trabalho nos moldes antimanicomiais.

\section{A reforma psiquiátrica e os trabalhadores da saúde mental - reflexões finais}

O movimento pela modificação do modelo de atenção à saúde mental no Brasil teve início com a participação dos trabalhadores da área. Isso não se deu por acaso. $\mathrm{O}$ ambiente manicomial tem-se mostrado um espaço de insalubridade e incômodo para os pacientes - no sentido mais tradicional dessa palavra -, mas também para os trabalhadores, pessoas que têm, no serviço de saúde, a possibilidade de sustentarem a si mesmas e às suas famílias. Embora tenham sido protagonistas do Movimento Nacional da Luta Manicomial, atualmente, são sobreviventes de um modelo de atenção falido e, em outros casos, ainda defensores insistentes de serviços humanizados que se recusam a se fixar na realidade do Distrito Federal.

Paulo Amarante (1997), ao explicar a gênese do movimento conhecido por Reforma Psiquiátrica, lembra que o contexto era de lutas contra a ditadura militar brasileira e que, em 1978, era formado o Movimento de Trabalhadores da Saúde Mental (MTSM). Esse movimento surgiu impulsionado por denúncias feitas por jovens médicos, em especial, quanto à forma como as pessoas eram tratadas nos serviços de saúde mental disponíveis à época. A partir dessa observação, verifica-se outra inversão dos contextos, uma vez que aqueles que, naquele momento, se manifestavam por outro modelo de atenção, são os mesmos que hoje, em categoria, lutam pela manutenção de seu status como protagonistas no tratamento e olham com maus olhos as experiências alternativas de cuidado em saúde mental.

Isso foi verificado em outras etapas desta pesquisa, não expressas aqui com profundidade. Em uma delas, se discutiram as dificuldades de implementação da reforma psiquiátrica no DF em grupo focal com profissionais de uma unidade de psiquiatria no maior hospital geral da unidade da federação. Na ocasião, os participantes eram da categoria médica, com exceção de uma assistente social. O discurso dos trabalhadores era, em geral, contrário à reforma psiquiátrica, e de questionamento da efetividade do modelo reformado de atendimento das demandas. Por outro lado, enfatizou o sofrimento dos profissionais, o não acesso à capacitação e a ausência de outras visóes que dialogassem sob o ponto de vista da saúde mental, e não da psiquiatria - termos considerados diferentes pelo grupo. Tal visão também foi expressa em análise das ediçóes do Jornal Brasiliense de Psiquiatria, publicado periodicamente pela Associação Psiquiátrica de Brasília (APBr).

Apesar das observaçóes feitas aqui, Tatiana Ramminger (2005), ao estudar a influência do processo de reforma psiquiátrica nos trabalhadores da saúde mental, e enfatizando os servidores vinculados aos serviços substitutivos, em especial CAPS, verifica a existência de um caráter peculiar da forma desses trabalhadores lidarem com a própria saúde. A autora afirma que

\section{[...] as politicas públicas direcionadas à saúde do trabalhador elegeram como foco principal os trabalhadores vinculados às organizaçôes pri- vadas, deixando uma importante lacuna na atenção aos servidores públicos e mais ainda para os trabalhadores da saúde. (RAMMIN- GER, 2005, p. 72).}

E complementa: "O servidor público, como trabalhador, não tem merecido investimento, apenas controle, em consonância com um longo histórico de desvalorização do setor público" (RAMMINGER, 2005, p. 77).

No estudo de Ramminger (2005), também foram notadas, nos CAPS, entre os trabalhadores, falas 
de compromisso ético, político e afetivo com a reforma psiquiátrica, o que culminou, inclusive, em percepçóes de maior valorização do próprio trabalho, identificada quando da ampliação das possibilidades de trabalho interdisciplinar. A transferência do foco do médico para a equipe psicossocial contribui para elevar a autoestima dos profissionais, que se veem participando efetivamente do processo terapêutico, identificam o resultado de seu trabalho no cotidiano e têm maior autonomia para exercê-lo.

Naquela pesquisa, a autora identificou que

Para alguns a Reforma Psiquiátrica auxiliou na prática reflexiva de seu trabalho, com uma 'politização constante das práticas clinicas, no cotidiano dos serviços. A reforma incutiu em mim um olhar critico dos processos de institucionalização das relaçôes cotidianas que tecem o trabalho nos serviços'. (entrevista com psicóloga apud RAMMINGER, 2005, p. 81).

Em ambos os estudos, os profissionais do CAPS relataram ser mais difícil trabalhar na perspectiva da reforma psiquiátrica, que exige inovação, criatividade e atitude. Afirmaram, também de forma similar, haver angústias advindas do trabalho com o transtorno mental, que é visto como sinônimo de instabilidade e gerador de impotência e frustração nos profissionais.

Cabe observar a diferença do discurso quanto ao motivo que leva ao sofrimento. No caso do CAPS, o próprio processo de trabalho advindo das modificaçōes trazidas pela reforma psiquiátrica é motivo de discussão, de questionamentos e de insatisfações da equipe, o que é esperado em um modelo de trabalho novo. Ainda assim, no discurso dos profissionais de Porto Alegre (RS), coletado pela autora mencionada, a dificuldade em relação ao cuidado voltado ao trabalhador é parcialmente justificada pela permanência dos gestores no "antigo modelo de produção" (RAMMINGER, 2005, p. 83).

No hospital psiquiátrico, não obstante, o sofrimento dos trabalhadores é justificado pela não implementação do novo modelo, pela dificuldade de diálogo com a equipe e pela não percepção de resultados concretos na vida dos usuários.

Ora, verifica-se que, de fato, o trabalho no âmbito da saúde mental exige muito dos servidores e traz à tona a necessidade de se construírem ambientes de trabalho adequados às demandas de usuários e profissionais. Náo se trata somente de tornar os locais mais claros e arejados - hipócrita e simplista percepção de humanização dos serviços de saúde -, mas de transformar as relaçóes estabelecidas entre as pessoas. A solução para as dificuldades enfrentadas pelas equipes de saúde mental é apontada por elas mesmas e consiste no aprofundamento do modelo antimanicomial, aberto e de interação e respeito à diversidade. Nota-se permanente necessidade de ampliação da liberdade, liberdade capaz de romper as amarras que prendem usuários, profissionais e a loucura ao hospício e às suas consequências violadoras de direitos.

Considerando o ciclo das políticas públicas (policy cycle) proposto por Klaus Frey (2000), que estabelece fases para a formulação e para a implementação das políticas, e a afirmação de Amarante (1997), que estabelece a reforma psiquiátrica como um processo permanente de reflexão sobre os aspectos que influenciam o modelo de atenção à saúde mental, é possível dizer que o momento atual é de avaliação do que foi feito até hoje na perspectiva antimanicomial. No mesmo sentido, deve-se restabelecer o debate acerca do significado da reforma psiquiátrica para os diferentes atores desse movimento, desde os usuários até os gestores, passando obrigatoriamente pelos profissionais que lidam diretamente com as demandas apresentadas, que são muito mais amplas do que doenças e situaçôes que dependem unicamente de medicamentos como solução. 


\section{Referências}

AMARANTE, P. D. Loucura, cultura e subjetividade: conceitos e estratégias, percursos e atores da reforma psiquiátrica brasileira. In: FLEURY, Sonia (org.). Saúde e democracia: a luta do CEBES. São Paulo: Lemos Editorial, 1997. p. 163-185.

BASAGLIA, F. A instituição negada: relato de um hospital psiquiátrico. Rio de Janeiro: Graal, 1985.

BRASIL. Ministério da Saúde. Coordenação geral de saúde mental, álcool e outras drogas. Saúde mental em dados, Brasília, a. VI, n. 9, jul. 2011. 21 p. Disponível em: <http://portal.saude.gov.br/portal/ arquivos/pdf/mentalemdados2011.pdf>.Acesso em: 08 fev. 2012.

BRASIL. Presidência da República. Lei no 10.216, de 06 de abril de 2001. Dispõe sobre a proteção e os direitos das pessoas portadoras de transtornos mentais e redireciona o modelo assistencial em saúde mental. Disponível em: <http://www.planalto.gov.br / ccivil_03/leis/leis_2001//10216.htm>. Acesso em: 01 mai. 2013.

DEMO, P. Metodologia científica em Ciências Sociais. São Paulo: Atlas, 1995.
FREY, K. Políticas públicas: um debate conceitual e reflexões referentes à prática da análise de políticas públicas no Brasil. Brasília: Ipea Publicações, jun 2000. Disponível em: <http://www.ipea.gov. br/pub/ppp/ppp21/Parte5.pdf>. Acesso em: 07 set. 2008.

GATTI, B. A. Grupo focal na pesquisa em Ciências Sociais e Humanas. Brasília: Liber Livro, 2005.

MINAYO, M. C. O desafio do conhecimento: pesquisa qualitativa em saúde. São Paulo/Rio de Janeiro: Hucitec/Abrasco, 1993.

PÈLBART, P. P. Manicômio mental: a outra face da clausura. In: LANCETTI, A. (org.). Saúdeloucura 2. São Paulo: Hucitec, 1990. p. 130138.

PEREIRA, P. A. P. Política social: temas e questões. São Paulo: Cortez, 2008.

RAMMINGER, T. Trabalhadores de saúde mental: reforma psiquiátrica, saúde dos trabalhadores e formas de subjetivação nos serviços de saúde mental. 2005. 118 f. Dissertação (Mestrado em Psicologia Social e Institucional) - Instituto de Psicologia, Universidade Federal do Rio Grande do Sul (UFRGS), Porto Alegre, 2005.

Recebido para publicação em Abril/2012

Versão final em Maio/2013

Conflito de interesse: não houve

suporte financeiro: inexistente 